\title{
Clinicopathological features and prognosis of gastroenteropancreatic neuroendocrine neoplasms in a Chinese population: a large, retrospective single-centre study
}

\author{
Meng Zhang ${ }^{1}$, Ping Zhao ${ }^{1}$, Xiaodan Shi', Ahong Zhao ${ }^{2}$, Lianfeng Zhang ${ }^{1}$ and Lin Zhou ${ }^{1 *}$
}

\begin{abstract}
Background: Gastroenteropancreatic neuroendocrine neoplasms (GEP-NENs) are the most common type of neuroendocrine tumors, accounting for more than half of neuroendocrine neoplasms (NENs). We performed a retrospective study in our center to investigate the clinicopathological features, risk factors of metastasis, and prognosis of GEP-NENs in a Chinese population.

Methods: Four hundred forty patients with GEP-NENs treated at the First Affiliated Hospital of Zhengzhou University between January 2011 and March 2016 were analyzed retrospectively. Multivariate logistic regression was performed to identify independent risk factors for metastasis of the tumors. The Kaplan-Meier method was used for survival analysis, and log-rank tests for comparisons among groups.

Results: Primary sites were the stomach (24.3\%), rectum (24.1\%), pancreas (20.5\%), esophagus (12.3\%), unknown primary origin (UPO-NEN) (8.0\%), duodenum (6.1\%). Three hundred eighty-nine of the 440 GEP-NENs cases (88.4\%) were non-functional tumors, and patients had non-specific symptoms, which could have led to delay in diagnosis and treatment. Neuroendocrine tumor, neuroendocrine carcinoma, and mixed adenoendocrine carcinoma were 56. $8 \%, 33.2 \%$ and 3.2\%, respectively, of the cases. One hundred thirty (29.5\%) of the tumors were G1, 120 (27.3\%) G2, and 190 (43.2\%) G3. The immunohistochemical positive rate of synaptophysin was 97.7\% and of chromogranin 48 . $7 \%$. Logistic regression analysis revealed that the diameter and pathological classification of tumors were the most important predictors for metastasis. The median survival time was 34 months for patients with well-differentiated neuroendocrine tumors grade G3 and 11 months for poorly differentiated neuroendocrine carcinoma. The median survival time of patients with localized disease, regional disease, and distant disease was 36 months, 15 month, and 6 months, respectively.
\end{abstract}

Conclusions: This study constitutes a comprehensive analysis of the clinicopathological features of GEP-NENs in a Chinese population. GEP-NENs may occur at any part of the digestive system. The diameter and pathological classification of tumor are the most important predictors for metastasis. The prognosis is poor for patients with poorly differentiated neuroendocrine cancers and distant metastases.

Keywords: Neuroendocrine neoplasms, Neuroendocrine tumors, Gastro enteropancreatic neuroendocrine tumors, Neuroendocrine cancers, Carcinoid tumor, Gastrinoma, Islet cell tumor

\footnotetext{
* Correspondence: ZL372@126.com

'Department of Gastroenterology, the First Affiliated Hospital of Zhengzhou University, No.1, East Jianshe Road, Zhengzhou 450052, China

Full list of author information is available at the end of the article
} International License (http://creativecommons.org/licenses/by/4.0/), which permits unrestricted use, distribution, and reproduction in any medium, provided you give appropriate credit to the original author(s) and the source, provide a link to the Creative Commons license, and indicate if changes were made. The Creative Commons Public Domain Dedication waiver (http://creativecommons.org/publicdomain/zero/1.0/) applies to the data made available in this article, unless otherwise stated. 


\section{Background}

Neuroendocrine neoplasms (NENs), which originate from neuroendocrine cells, comprise a heterogeneous family with a broad spectrum of clinical behavior [1]. The neoplasms occur in diverse sites throughout the body, and more than half are gastroenteropancreatic NENs (GEP-NENs) [2]. According to the Surveillance, Epidemiology, End Results database (SEER), which has the largest epidemiologic series, the incidence of NENs has risen substantially over the past 30 years [2]. Although the prevalence of GEP-NENs seems to be increasing in China, there is no accurate database of the characteristics of GEP- NENs in Chinese patients.

In 2010, the World Health Organization [3] proposed a new classification of NENs, with comparisons of clinical, pathological, therapeutic, and prognostic factors. In western countries, the epidemiology, treatment, and survival rates of NENs have been well-studied [1, 2], but comparable information in Asian populations is limited $[4,5]$. In order to investigate the clinical pathological characteristics, risk factors of metastasis, and prognosis of NENs in a Chinese population, we performed a comprehensive retrospective review of the recent 5-year experience with this disease in our center.

\section{Methods}

\section{Patients}

The study was conducted on 440 patients from the First Affiliated Hospital of Zhengzhou University between January 2011 and March 2016. The study was approved by the hospital's Ethics Committee, and informed consent was obtained from all patients. All patients had received a pathological diagnosis of GEP-NENs according to the World Health Organization classification [3] and the China Consensus Guideline [6]. Collected information consisted of clinical characteristics (gender, age, location of tumors, and symptoms); diagnostic procedures (endoscopic and radiographic); tumor characteristics (size, grading, histopathology of primary tumor, metastases); treatments; and follow-up.

The pathological diagnosis of the NENs depended on typical morphological findings and immunohistochemical staining of chromogranin (CgA) and/or synaptophysin (Syn) [7]. Grading was based on morphological criteria and tumor proliferative activity. According to the Ki-67 index, the grading was G1, G2 and G3 $\leq 2 \%$, $3 \sim 20 \%,>20 \%$, respectively. Similarly, tumors with mitotic rates of less than two in 10 high-power fields (HPF) were classified as G1, $2 \sim 20 / \mathrm{HPF}$ as G2, and >20/HPF as G3. If the grading of the Ki-67 index differed from that of the mitotic rate, the higher of the two was given priority. Therefore, GEP-NENs were classified as neuroendocrine tumor (NET) (G1 and G2), neuroendocrine carcinoma (NEC) (G3), and mixed adenoendocrine carcinoma (MANEC) (G3) [3, 4]. The well-differentiated G3 NENs (Ki-67 positive index $>20 \%$; generally less than $60 \%)$ were classified as well-differentiated NET (NET G3) $[8,9]$.

\section{Statistical analysis}

All statistical analyses were performed using SPSS 17.0 for Windows (IBM Corporation. Armonk, NY, USA). Normally distributed continuous variables were expressed as mean and standard deviation, and statistical differences between groups were assessed with the independent samples t-tests. Differences in categorical variables were compared with chi-square test or Fisher 's exact test. Multivariate logistic regression was performed to identify independent risk factors for tumor metastasis. Overall survival was defined as the time from diagnosis to death or, in living patients, the time to last follow-up. Survival curves were drawn according to the KaplanMeier method, and differences between subgroups were assessed with the log-rank test. $P$-values $<0.05$ were considered statistically significant.

\section{Results \\ Clinical features}

Among the 440 patients with GEP-NENs, 259 (58.9\%) were men and 181 (41.1\%) were women; the male to female ratio was 1.43. Ages ranged from 9 to 86 years, and the mean age was $(54.3 \pm 13.5)$ years. The mean age of men was $(55.5 \pm 13.5)$, women was $(52.7 \pm 13.3)$. The most common tumor site was the stomach $(24.3 \%, 107 /$ $440)$, followed by the rectum $(24.1 \%, 106 / 440)$, pancreas (20.5\%, 90/440), esophagus $(12.3 \%, 54 / 440)$, unknown primary origin (UPO-NEN) $(8.0 \%, 35 / 440)$, duodenum $(6.1 \%, 27 / 440)$, and other sites: appendix, jejunum/ileum, and colon $(4.7 \%, 21 / 440)$.

Non-functional tumors comprised the majority of GEP-NENs (389/440, 88.4\%); the other 51 (11.6\%) were functional. The most frequent initial presentation was abdominal pain $(101 / 440,23 \%)$, which was not specific for the diagnosis of tumor, followed by dysphagia (45/ $440,10.2 \%)$, bleeding $(38 / 440,8.6 \%)$, diarrhea (19/440, $4.3 \%)$, jaundice $(16 / 440,3.6 \%)$, and abdominal distention. Forty-one $(9.3 \%)$ cases were found during routine physical examination. Insulinoma comprised 90.2\% (46/51) of functional tumors, all of which were located in the pancreas, and typical symptoms were those of hypoglycemia and epileptic seizure. Seven patients with insulinoma were treated as epilepsy before the diagnosis of NENs, and 2 cases were initially treated as psychiatric disorders. The other functional tumors were gastrinoma (3/51, 5.9\%) and glucagonoma (2/51, 3.9\%), expressed as multiple refractory peptic ulcer, diarrhea, secondary diabetes mellitus and cutaneous erythema. There was no patient presented with carcinoid syndrome in our study. 


\section{Imaging studies}

The results of imaging examinations are summarized in Table 1. All imaging examinations can be found in any grade of tumors. Endoscopy, endoscopic ultrasound (EUS) and positron emission computed tomography imaging (PET-CT, using with 18F-FDG) were positive in $>90 \%$ of cases. Magnetic resonance imaging was the least often positive (79.5\%). But MRI and PET-CT, was performed in only about $10 \%$ of patients, respectively. MRI is mainly used for the detection of pancreatic and liver tumors and PET-CT for tumors in any part of the digestive system. EUS was performed on 41 patients, of which a lesion was found in 38 patients. At endoscopy, which is used for the detection of gastrointestinal tract tumors, the GEP-NENs usually appeared as ulcers or polypoid prominences. Ultrasound and endoscopic ultrasound (EUS) usually revealed the GEP-NENs as hypoechoic and well-vascularized masses. By computed tomography (CT) and magnatic resonance imaging (MRI), the tumors appeared as local space-occupying lesions, with heterogeneous enhancement on contrast-enhanced CT. PET-CT usually revealed high glucose metabolism in GEP-NENs, especially in poorly differentiated NENs. Seven tumors, initially identified in the liver, were found located in the pancreas by EUS-guided fine-needle biopsy.

\section{Histopathologic characteristics}

The histopathologic characteristics (size, World Health Organization 2010 classification, and metastases) of the 440 GEP-NENs are given in Table 2. The most common tumor type was NET (250, 56.8\%), followed by NEC $(146,33.2 \%)$ and MANEC (14, 3.2\%); the other 30 cases of G3 were classified as NET G3. Local infiltration and lymphatic metastasis occurred in 63\% (277/440) and $12.3 \%(54 / 440)$ of patients, respectively. Distant metastases were found in 90 (20.5\%) patients at initial diagnosis; during follow-up, the number increased to 109 (24.8\%). Distant metastases were present at initial diagnosis in $38.4 \%(73 / 190)$ of patients with G3 tumors. The most

Table 1 Characteristics of imaging studies

\begin{tabular}{lllll}
\hline Imaging study & Site & Cases tested & \multicolumn{2}{l}{ Positive tests } \\
\cline { 4 - 5 } & & $(\mathrm{n})$ & $\mathrm{n}$ & $\%$ \\
\hline Endoscopy & gastrointestinal & 226 & 224 & $99.1 \%$ \\
EUS & $\begin{array}{l}\text { pancreas, duodenum, } \\
\text { stomach }\end{array}$ & 41 & 38 & $92.7 \%$ \\
Ultrasound & pancreas, liver, biliary tree & 165 & 143 & $86.7 \%$ \\
CT scan & all of above & 321 & 274 & $85.4 \%$ \\
MRI & pancreas, liver & 39 & 31 & $79.5 \%$ \\
FDG PET-CT & all of above & 29 & 27 & $93.1 \%$ \\
\hline
\end{tabular}

EUS endoscopic ultrasonography, $C T$ computed tomography, MRI magnetic resonance imaging, FDG PET-CT fluorodeoxyglucose positron emission computed tomography imaging frequent site of distant metastasis was liver (67/109, $61.5 \%)$, followed by peritoneum $(18.3 \%, 20 / 109)$, lung $(10.1 \%, 11 / 109)$ and bone $(6.4 \%, 7 / 109)$. Among the $67 \mathrm{pa}-$ tients with liver metastases, 55 presented with synchronous lesions and 12 with metachronous lesions during follow-up. The positive rates of immunohistochemistry of Syn and CgA were 97.7\% (416/426) and 48.7\% (135/277, respectively.

The clinicopathologic characteristics related to metastasis were listed in Table 3. The risk factors of GEP-NENs metastases were then analyzed by the logistic regression method. Multivariate logistic regression analysis revealed that the diameter and pathological classification of tumors were the most important predictors for metastasis (Table 4).

\section{Therapeutic interventions}

About two-thirds of the patients (62.5\%; 275/440) underwent an operation with curative intent or palliation; 50 patients were treated with endoscopic radical surgery, mainly for rectal lesions. Seventy-three patients received chemotherapy, 34 of whom received postoperative adjuvant chemotherapy. The combination of cisplatin and etoposide was the most widely used chemotherapeutic agents. Six patients received octreotide, a somatostatin analogue, as a biological therapy combined with surgery or chemotherapy. Local-regional therapies, such as transcatheter hepatic arterial chemoembolization, radiofrequency, or other ablative techniques were used in eight patients.

\section{Survival and prognostic factors}

Four hundred fourteen of the 440 patients were followed for periods of 3-60 months. Due to the short follow-up time and a low number of deaths in NET (G1 and G2) patients, median survival time was not obtained for them during the observation period. The 1-, 3- and 5year survival rates of all patients were $78.7 \%, 60.8 \%$ and 54.5, respectively. The 1-, 3- and 5- year survival rates of patients with G3 lesions were 54.3\%, 19.4\% and 7.8\%, respectively. The major causes of death were tumorrelated complications $(82.7 \%)$, treatment-related adverse events (13.4\%), and other diseases (3.9\%). For patients with G3 NENs, age, gender, primary tumor site, differentiation, and characterization of metastasis were analyzed in order to identify prognostic factors for survival (Table 5). Univariate analysis confirmed that patients with NET G3 and patients without regional or distant metastasis survived longer than did other patients with NENs G3, but age, gender, and primary tumor site had no discernable impact on overall survival. Median overall survival among all the patients with G3 NENs was 13.0 months, and survival was significantly longer for these patients (median 34 months) than for those with NEC (median 11 months). Median overall survival of patients with 
Table 2 Histopathological characteristics of the GEP-NENs $(n=440)$

\begin{tabular}{|c|c|c|c|c|c|c|c|c|c|c|}
\hline & $\begin{array}{l}\text { Stomach } \\
n=107\end{array}$ & $\begin{array}{l}\text { Esophagus } \\
n=54\end{array}$ & $\begin{array}{l}\text { Duodenum } \\
n=27\end{array}$ & $\begin{array}{l}\text { Jejunum/ileum } \\
n=8\end{array}$ & $\begin{array}{l}\text { Colon } \\
n=5\end{array}$ & $\begin{array}{l}\text { Appendix } \\
n=8\end{array}$ & $\begin{array}{l}\text { Rectum } \\
n=106\end{array}$ & $\begin{array}{l}\text { UPO-NEN } \\
n=35\end{array}$ & $\begin{array}{l}\text { Pancreas } \\
n=90\end{array}$ & $\begin{array}{l}\text { Total } \\
n=440(\%)\end{array}$ \\
\hline \multicolumn{11}{|l|}{ Size } \\
\hline$<2 \mathrm{~cm}$ & 24 & 5 & 15 & 1 & 0 & 3 & 67 & 4 & 37 & 156(35.5) \\
\hline $2 \sim 4 \mathrm{~cm}$ & 12 & 10 & 3 & 2 & 0 & 0 & 2 & 6 & 16 & $51(11.6)$ \\
\hline$>4 \mathrm{~cm}$ & 31 & 12 & 3 & 3 & 2 & 1 & 1 & 8 & 11 & $72(16.4)$ \\
\hline Unclear & 40 & 27 & 6 & 2 & 3 & 4 & 36 & 17 & 26 & 161(36.6) \\
\hline \multicolumn{11}{|l|}{ WHO2010 } \\
\hline G1 & 17 & 0 & 6 & 1 & 1 & 5 & 70 & 3 & 27 & $130(29.5)$ \\
\hline $\mathrm{G} 2$ & 21 & 1 & 11 & 2 & 0 & 2 & 26 & 7 & 50 & $120(27.3)$ \\
\hline G3 & 69 & 53 & 10 & 5 & 4 & 1 & 10 & 25 & 13 & 190(43.2) \\
\hline \multicolumn{11}{|l|}{ Metastases } \\
\hline Local & 43 & 16 & 18 & 4 & 2 & 8 & 94 & 19 & 73 & $277(63)$ \\
\hline Loco-regional & 28 & 14 & 1 & 2 & 1 & 0 & 3 & 4 & 1 & $54(12.3)$ \\
\hline Distant & 36 & 24 & 8 & 2 & 2 & 0 & 9 & 12 & 16 & $109(24.8)$ \\
\hline
\end{tabular}

Table 3 Clinicopathological characteristics related to metastasis

\begin{tabular}{|c|c|c|c|c|c|}
\hline Pathologic characteristics & Total & Metastasis & Non-metastasis & $x^{2}$ & $P$ \\
\hline \multicolumn{6}{|l|}{ Sex } \\
\hline Male & 259 & $112(43.2 \%)$ & $147(56.8 \%)$ & \multirow[t]{2}{*}{10.370} & \multirow[t]{2}{*}{$<0.01$} \\
\hline Female & 181 & $51(28.2 \%)$ & 130(71.8\%) & & \\
\hline \multicolumn{6}{|l|}{ Age } \\
\hline$\leq 50$ & 158 & $33(20.9 \%)$ & $125(79.1 \%)$ & \multirow[t]{2}{*}{27.602} & \multirow[t]{2}{*}{$<0.01$} \\
\hline$>50$ & 282 & $130(46.1 \%)$ & $152(53.9 \%)$ & & \\
\hline \multicolumn{6}{|l|}{ Site } \\
\hline Stomach & 107 & $64(59.8 \%)$ & $43(40.2 \%)$ & \multirow[t]{3}{*}{67.249} & \multirow[t]{3}{*}{$<0.01$} \\
\hline Rectum & 106 & $12(11.3 \%)$ & $94(88.7 \%)$ & & \\
\hline Pancreas & 90 & 17(18.9\%) & 73(81.1\%) & & \\
\hline \multicolumn{6}{|l|}{ Functional status } \\
\hline Functional & 51 & $2(3.9 \%)$ & 49 (96.1\%) & \multirow[t]{2}{*}{25.556} & \multirow[t]{2}{*}{$<0.01$} \\
\hline Nonfunctional & 389 & $161(41.4 \%)$ & $228(58.6 \%)$ & & \\
\hline \multicolumn{6}{|l|}{ Tumor diameter } \\
\hline$\leq 2 \mathrm{~cm}$ & 156 & $14(9.0 \%)$ & 142(91.0\%) & \multirow[t]{3}{*}{80.879} & \multirow[t]{3}{*}{$<0.01$} \\
\hline $2-4 \mathrm{~cm}$ & 51 & 23(45.1\%) & $28(54.9 \%)$ & & \\
\hline$\geq 4 \mathrm{~cm}$ & 72 & $47(65.3 \%)$ & $25(34.7 \%)$ & & \\
\hline \multicolumn{6}{|l|}{ Tumor grading } \\
\hline G1 & 130 & $4(3.1 \%)$ & 126(96.9\%) & \multirow[t]{3}{*}{182.475} & \multirow[t]{3}{*}{$<0.01$} \\
\hline G2 & 120 & $22(18.3 \%)$ & $98(81.7 \%)$ & & \\
\hline G3 & 190 & 137(72.1\%) & $53(27.9 \%)$ & & \\
\hline \multicolumn{6}{|l|}{ Tumor type } \\
\hline NET & 250 & $26(10.4 \%)$ & $224(89.6 \%)$ & \multirow[t]{3}{*}{182.746} & \multirow[t]{3}{*}{$<0.01$} \\
\hline NEC & 146 & $113(77.4 \%)$ & $33(22.6 \%)$ & & \\
\hline MANEC & 14 & 8 (57.1\%) & 6 (42.9\%) & & \\
\hline
\end{tabular}


Table 4 The logistic regression for the relationship between the clinicopathological characteristics and metastasis

\begin{tabular}{|c|c|c|c|c|c|c|c|}
\hline Variable & Coefficient & Standard Error & Wald $x^{2}$ & $P$ & Odds ratio & $95 \% \mathrm{Cl}$ & \\
\hline Tumor diameter & 0.790 & 0.239 & 10.909 & 0.001 & 2.203 & 1.379 & 3.521 \\
\hline Grading & 1.998 & 0.326 & 37.510 & $<0.01$ & 7.373 & 3.890 & 13.974 \\
\hline Constant & -6.887 & 0.811 & 72.106 & $<0.01$ & 0.001 & - & - \\
\hline
\end{tabular}

localized G3 NENs was 36 months, 15 months for patients with regional disease, and 6 months for patients with distant disease. Survival curves are displayed in Fig. 1, a-f.

\section{Discussion}

This retrospective study explored the clinicopathological characteristics, risk factors of metastasis, treatment, and prognosis of GEP-NENs in a relatively large population of Chinese patients. Tumors located at any possible site within the digestive system were analyzed. In addition, the NENs G3 were classified as NET G3 (well-differentiated NET with a G3 grading) or NEC, and the prognoses of these were compared. The study will contribute to establishing a database of the epidemiology, clinical pathological features, treatment, and prognosis of GEP-NENs in Chinese or Asian patients. It also will permit comparisons between GEP-NENS in these populations and those in western nations.

As others have reported [2], we found that most NENs are present in the gastrointestinal tract. The distribution of GEP-NENs in our population (stomach $>$ rectum $>$ pancreas $>$ duodenum) was similar to that found in Korean [10], Japanese [11], and other Chinese populations [4, 12, 13]. A large-scale analysis of GEP-NENs in the SEER database from the United States in North America found that the rectum and jejunum/ileum were the most common sites for NENs [2]. Ethnic, regional and sample-size differences may lead to differences in the reported distribution of the primary sites of GEP-NENs.

NENs can be classified as functional and nonfunctional tumors according to the presence or absence of symptoms associated with hormone overproduction [14]. In this study, the majority of tumors were nonfunctional, which may have led to misdiagnosis or delay in making the diagnosis and treating the patients promptly. The study found also that insulinoma comprised the largest number of functional NENs and accounted for about one-half of all NENs. None of the patients presented with carcinoid syndrome due to overproduction of 5-hydroxytryptamine, a finding similar to a low reported frequency of these tumors in Asian

Table 5 Overall survivals of G3-NENs

\begin{tabular}{|c|c|c|c|c|c|}
\hline \multirow[t]{2}{*}{ Factors } & \multicolumn{5}{|c|}{ Overall survival } \\
\hline & Number & Mean(months) & $95 \% \mathrm{Cl}$ & $x^{2}$ & $P$ \\
\hline All patients & 180 & 13 & $10.9-15.1$ & & \\
\hline Sex & & & & 2.386 & 0.122 \\
\hline Male & 123 & 14 & $11.7-16.3$ & & \\
\hline Female & 57 & 11 & 6.4-15.6 & & \\
\hline Age & & & & 0.466 & 0.495 \\
\hline$\leq 50$ & 32 & 16 & $11.2-20.8$ & & \\
\hline$>50$ & 148 & 13 & $11.0-15.0$ & & \\
\hline Site & & & & 0.520 & 0.771 \\
\hline Gastrointestinal tract & 143 & 13.5 & $11.8-15.2$ & & \\
\hline Pancreas & 13 & 8 & $5.0-11.0$ & & \\
\hline Others & 24 & 12 & $2.9-21.1$ & & \\
\hline Differentiation & & & & 9.186 & 0.002 \\
\hline NEC & 137 & 11 & $8.5-13.5$ & & \\
\hline NET G3 & 30 & 34 & $10.7-57.3$ & & \\
\hline Metastasis & & & & 85.305 & 0.000 \\
\hline Local & 48 & 36 & $25.9-46.1$ & & \\
\hline Loco-reginal & 45 & 15 & $13.9-16.2$ & & \\
\hline Distant & 71 & 6 & $4.7-7.3$ & & \\
\hline
\end{tabular}



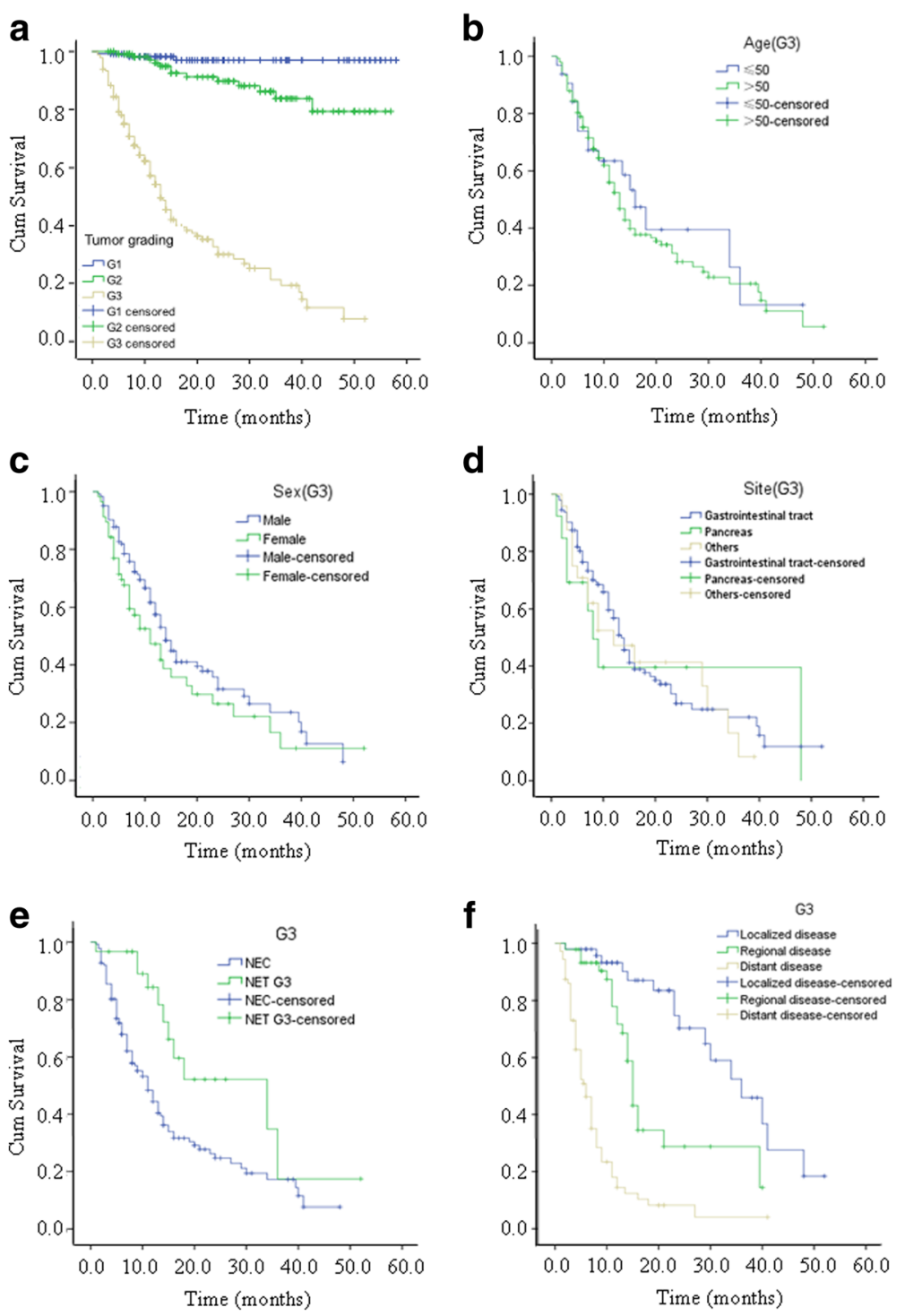

Fig. 1 Kaplan-Meier analysis of overall survival. a Overall survival by histological grading. b Overall survival by age of of patients with G3 tumors. c Overall survival by sex of patient with G3 tumors. $\mathbf{d}$ Overall survival by site of G3 tumors. e Overall survival by differentiation of G3 tumors. $\mathbf{f}$ Overall survival by characteristics of metastasis of G3 tumors

populations $[4,12,13]$. However, the incidence of carcinoid syndrome $(11.5 \%$ to $31.1 \%)$ in the Western population is relatively high [15-17]. Carcinoid syndrome occurs mainly in the neuroendocrine neoplasms of jejunum/ileum. In the western population, the proportion of neuroendocrine neoplasms of jejunum/ileum is high, which is only $1.8 \%$ in our study. These data also indicated that functional NENs were mainly located in the pancreas, and the gastrointestinal neuroendocrine neoplasms were mainly non-functional. Several studies have used serum CgA as a circulating biomarker of GEPNENs, with sensitivity and specificity rates in the range of $60 \%$ to $100 \%$ [18]. Serum CgA was mot measured in our series, but we favor measuring it since it is a simple screening test and can shorten the time needed to make the diagnosis of a NEN.

Since non-functional GEP-NENs in the early stage often have no specific symptoms, imaging examinations are especially important in locating the tumors and assessing their extent. CT scan was the most frequently used imaging modality, whereas endoscopy had the highest yield of tumor detection (99.1\%). Because of its convenience and non-invasive nature, ultrasound was chosen as the first screening method for solid organs, where the detection rate was $87 \%$. EUS provides unique advantages in evaluating the upper gastrointestinal tract and pancreas, especially for tumors less than $1.0 \mathrm{~cm}$ in diameter and micrometastases [19]. The 92.3\% detection 
rate of GEP-NENs in our series is within the range (91.9\% to $97.4 \%)$ reported by others $[4,13]$. The most common primary site of metastatic liver NENs is the pancreas, so EUS-guided fine-needle biopsy of the pancreas in patients with metastatic liver NENs is helpful for early detection of the primary lesion. Somatostatin receptor scintigraphy is considered a comprehensive imaging modality for many neuroendocrine tumors $[20,21]$, but, unfortunately, this method is not available in our institution.

The definitive diagnosis of GEP-NENs depends on the pathological analysis of biopsy, including cell morphology and immunohistochemical staining. The World Health Organization revised its nomenclature and classification of GEP-NENs in 2010 [3], and China reported its own classification system soon thereafter [6]. Rates of positive immunohistochemical staining for Syn (97.7\%) and CgA (48.7\%) in our series indicate that Syn has high sensitivity, and CgA has high specificity [22].

In our series, the rate of distant metastases $(20.5 \%$ initially and $24.8 \%$ during follow-up) was modestly lower than the rate reported from Spain (44\%) [23] but in the range reported from the United States (21\%) [2] and in other Chinese series $(10.4 \%$ to $23.0 \%)$ [4, 12, 13]. The liver was the most frequent site of metastatic tumors. The rate of distant metastases at diagnosis was high, which indicates that GEP-NENs, especially the nonfunctional tumors, were occult, a characteristic that could have led to delayed diagnosis and increased risk of metastasis. The rate of transfer factors of GEP-NENs was related to location of the primary tumors, with the metastasis rate of gastric NENs significantly higher than that of pancreatic or rectal tumors. The reported rate of metastasis of pancreatic NENs (69.2\%) in a Western population [24] was higher than in our series (18.9\%); the possible reasons for this difference could be differences in the ratio of non-functional to functional pancreatic NENS, with differences in time duration between onset of symptoms and diagnosis, or sample size. Also, we admit that the rate of missed diagnosis of pancreatic NENs in China may be high.

Surgical treatment is the first choice for GEP-NENs, even if there are nodal or distant metastases. When possible, the primary tumor should be removed, lymph nodes dissected, and distant metastases excised [25]. In this study, 275 patients underwent surgical treatment, including radical surgery and palliative surgery, with 50 patients treated by endoscopy. Early diagnosis is crucial in order that resection can be performed before local invasion or distant disease occurs.

Chemotherapy is the first treatment option for poorly differentiated or rapidly progressive, advanced GEPNENs. In our series, as in other reports [26], the combination of cisplatin and etoposide was the most widely used chemotherapy regimen. Radiofrequency ablation, transcatheter hepatic arterial chemoembolization, or other ablative treatments, which can be used to treat liver lesions, were used in only 8 patients in our series, and only 6 patients were treated with biological therapy. Limited financial resources in our area may have contributed to the infrequent use of newer or experimental therapies for GEP-NENs such as peptide receptor radionuclide therapy and targeted agents.

The prognosis of GEP-NENs is more favorable than that of adenocarcinomas of the digestive system. In our series, the overall 5 -year survival rate was $54.5 \%$, which is similar to that quoted the SEER registry and in Chinese data $[2,4]$, but lower than the rate in some Europe countries [23]. These differences may be due to the ethnic, regional, or simple-size differences. Due to the short follow-up time and a low number of deaths in NET (G1 and G2) patients, we did not determine median survival times during the observation period, and limited our survival estimates to patients with NENs G3; their 5year survival rate was $7.8 \%$, which is similar to rates of $6 \%-11 \%$ in European series [27]. Very few data comparing NET G3 and NEC are available $[8,9]$. In our series, there was a significant difference in the survival time between the G3 NET and NEC (34 months vs 11 months), which are similar results to those of other series $[9,28$, 29]. While most NENs G3 are poorly differentiated, a subgroup of well-differentiated NET with G3 grading is not reflected in the latest Word Health Organization classification. It has been suggested that these two highgrade cancers differ in prognosis, somatostatin receptor scintigraphy uptake and response to chemotherapy regimens $[29,30]$ and therefore should be classified separately. The small size of our series of NET G3 tumors precluded doing a multivariate analysis to estimate their independent prognostic factors; evaluation in a larger population of such tumors is needed. Unsurprisingly, we found that distant metastasis of GEP-NENs was associated with a poor outcome; thus, early diagnosis of the tumors is very important in improving patients' prognosis.

\section{Conclusions}

The results of this study provide a comprehensive analysis of the clinicopathological features of GEP-NENs in a Chinese population. It was found that GEP-NENs may originate from any part of the digestive system, and the majority are non-functional tumors, whose early symptoms are occult, thus often resulting in delay in the diagnosis being made. Tumor diameter and classification are important factors in predicting metastasis. The prognosis of GEP-NENs is more favorable than that of gastrointestinal carcinomas, but the prognosis is poor for patients with high-grade poorly differentiated NEC and distant metastases. It is our hope that this extensive 
analysis of GEP-NENs will improve physicians' knowledge of the tumors and result in earlier recognition and treatment for Chinese patients. And limited financial resources in our area may lead to the infrequent use of newer or experimental therapies for GEP-NENs. Perhaps this could be a probable explanation on poorer prognosis compared to Western data.

\begin{abstract}
Abbreviations
CgA: Chromogranin; CT: Computed tomography; EUS: endoscopic ultrasound; GEP-NENs: Gastroenteropancreatic neuroendocrine neoplasms; HPF: High-power fields; MANEC: Mixed adenoendocrine carcinoma; MRI: Magnatic resonance imaging; NEC: Neuroendocrine carcinoma; NENs: Neuroendocrine neoplasms; NET G3: Well-differentiated NET with a G3 grading; NET: Neuroendocrine tumor; PET-CT: positron emission computed tomography imaging; SEER: Surveillance, Epidemiology, End Results database; Syn: Synaptophysin; WHO: World Health Organization
\end{abstract}

\section{Acknowledgements}

Not applicable.

\section{Funding}

This work was support by National Nature Science Foundation of China $(81,472,325 ; 81,001,103)$, and Health, Science and Technology Chuang-Xin Talent Program of Henan Province, and Youth Innovation Fund of the First Affiliated Hospital of Zhengzhou University.

\section{Availability of data and materials}

The data that support the findings of this study are available from the authors on reasonable request.

\section{Authors' contributions}

LZ conceived and designed the study. MZ, AHZ and LFZ collected pathological data and analyzed the data. MZ, PZ and XDS collected clinical data. MZ wrote the original draft of the manuscript. All co-authors revised and approved the current manuscript.

\section{Ethics approval and consent to participate}

Ethical approval for this study was obtained from the Ethics Committee of the First Affiliated Hospital of Zhengzhou University. Zhengzhou, China. Informed consent was obtained prior to the conduct of any study-related procedures. And written consent of minors was obtained from the participants' parents or legal guardians. The study was performed in compliance with the Declaration of Helsinki and the Good Clinical Practice (GCP) Guidelines.

\section{Consent for publication}

Not applicable.

\section{Competing interests}

The authors declare that they have no competing interests.

\section{Publisher's Note}

Springer Nature remains neutral with regard to jurisdictional claims in published maps and institutional affiliations.

\footnotetext{
Author details

'Department of Gastroenterology, the First Affiliated Hospital of Zhengzhou University, No.1, East Jianshe Road, Zhengzhou 450052, China. ${ }^{2}$ Department of Pathology, the First Affiliated Hospital of Zhengzhou University, No.1, East Jianshe Road, Zhengzhou 450052, China.
}

Received: 3 January 2017 Accepted: 30 June 2017

Published online: 13 July 2017

\section{References}

1. Modlin IM, Lye KD, Kidd M. A 5-decade analysis of 13,715 carcinoid tumors. Cancer. 2003;97(4):934-59.
2. Yao JC, Hassan M, Phan A, Dagohoy C, Leary C, Mares JE, Abdalla EK, Fleming JB, Vauthey JN, Rashid A. One hundred years after "carcinoid": epidemiology of and prognostic factors for neuroendocrine tumors in 35,825 cases in the United States. J Clin Oncol. 2008;26(18):3063-72.

3. Bosman FT, Carneiro F, Hruban RH, Theise ND. WHO classification of tumours of the digestive system; 2010. p. 1089.

4. Wang $Y$-h, Lin $Y$, Xue L, Wang J-h, Chen M-h, Chen J. Relationship between clinical characteristics and survival of gastroenteropancreatic neuroendocrine neoplasms: A single-institution analysis (1995-2012) in South China. BMC Endocr Disord. 2012;12(1):1-9.

5. Lim T, Lee J, Kim JJ, Lee JK, Lee KT, Kim YH, Kim KW, Kim S, Sohn TS, Dong WC. Gastroenteropancreatic neuroendocrine tumors: Incidence and treatment outcome in a single institution in Korea. Asia Pac J Clin Oncol. 2011;7(7):293-9.

6. Chinese Pathologic Consensus Group for Gastrointestinal and Pancreatic Neuroendocrine N. Chinese pathologic consensus for standard diagnosis of gastrointestinal and pancreatic neuroendocrine neoplasm. Chinese Journal of Pathology. 2011;40(4):257-62.

7. Erickson LA, Lloyd RV. Practical markers used in the diagnosis of endocrine tumors. Adv Anat Pathol. 2004;11(4):175-89.

8. Coriat R, Walter T, Terris B, Couvelard A, Ruszniewski P.

Gastroenteropancreatic Well-Differentiated Grade 3 Neuroendocrine Tumors: Review and Position Statement. Oncologist. 2016;21(10):1191-9.

9. Heetfeld M, Chougnet CN, Olsen IH, Rinke A, Borbath I, Crespo G, Barriuso J, Pavel M, O'Toole D, Walter T. Characteristics and treatment of patients with G3 gastroenteropancreatic neuroendocrine neoplasms. Endocr Relat Cancer. 2015;22(4):657-64.

10. Cho MY, Kim JM, Jin HS, Kim MJ, Kim KM, Kim WH, Kim H, Kook MC, Park DY, Lee JH. Current Trends of the Incidence and Pathological Diagnosis of Gastroenteropancreatic Neuroendocrine Tumors (GEP-NETs) in Korea 20002009: Multicenter Study. Chin J Cancer Res. 2012;44(3):157-65.

11. Ito T, Sasano H, Tanaka M, Osamura RY, Sasaki I, Kimura W, Takano K, Obara T, Ishibashi M, Nakao K. Epidemiological study of gastroenteropancreatic neuroendocrine tumors in Japan. J Gastroenterol. 2010;45(2):234-43.

12. Jiao X, Li Y, Wang H, Liu S, Zhang D, Zhou Y. Clinicopathological features and survival analysis of gastroenteropancreatic neuroendocrine neoplasms: a retrospective study in a single center of China. Chin J Cancer Res. 2015; 27(3):258-66.

13. Zeng YJ, Liu L, Wu H, Lai W, Cao JZ, Xu HY, Wang J, Chu ZH. Clinicopathological features and prognosis of gastroenteropancreatic neuroendocrine tumors: analysis from a single-institution. Asian Pac J Cancer Prev. 2013;14(10):5775-81.

14. Klimstra DS, Modlin IR, Adsay NV, Chetty R, Deshpande V, Gonen M, Jensen RT, Kidd M, Kulke MH, Lloyd RV. Pathology reporting of neuroendocrine tumors: application of the Delphic consensus process to the development of a minimum pathology data set. Am J Surg Pathol. 2010;34(3):300-13.

15. Pape UF, Böhmig M, Berndt U, Tiling N, Wiedenmann B, Plöckinger U. Survival and Clinical Outcome of Patients with Neuroendocrine Tumors of the Gastroenteropancreatic Tract in a German Referral Center. Ann N Y Acad Sci. 2004;1014(1):222-33.

16. Pape UF, Berndt U, Müllernordhorn J, Böhmig M, Roll S, Koch M, Willich SN, Wiedenmann B. Prognostic factors of long-term outcome in gastroenteropancreatic neuroendocrine tumours. Endocr Relat Cancer. 2008; 15(4):1083-97.

17. Ploeckinger U, Kloeppel G, Wiedenmann B, Lohmann R. The German NETregistry: an audit on the diagnosis and therapy of neuroendocrine tumors. Neuroendocrinology. 2009;90(4):349-63.

18. Diaz Perez JA, Curras Freixes M. Chromogranin A and neuroendocrine tumors. Endocrinologia y nutricion: organo de la Sociedad Espanola de Endocrinologia y Nutricion. 2013;60(7):386-95.

19. Iug S, Solodinina EN, Egorov AV, Shishkin KV, Novozhilova AV, Kurushkina NA. Endoscopic ultrasonography in the diagnosis of neuroendocrine tumors of the pancreas. Eksp Klin Gastroenterol. 2009;10:37-45.

20. Hofman MS, Lau WF, Hicks RJ. Somatostatin receptor imaging with 68Ga DOTATATE PET/CT: clinical utility, normal patterns, pearls, and pitfalls in interpretation. Radiographics. 2015;35(2):500-16.

21. Geijer H, Breimer LH. Somatostatin receptor PET/CT in neuroendocrine tumours: update on systematic review and meta-analysis. Eur J Nucl Med Mol Imaging. 2013;40(11):1770-80.

22. O'Toole D, Grossman A, Gross D, Delle FG, Barkmanova J, O'Connor J, Pape UF, PI枚ckinger U. ENETS Consensus Guidelines for the Standards of Care in 
Neuroendocrine Tumors: biochemical markers. Neuroendocrinology. 2009; 90(2):194-202.

23. Garcia-Carbonero R, Capdevila J, Crespo-Herrero G, Diaz-Perez JA, Martinez Del Prado MP, Alonso Orduna V, Sevilla-Garcia I, Villabona-Artero C,

Beguiristain-Gomez A, Llanos-Munoz M. Incidence, patterns of care and prognostic factors for outcome of gastroenteropancreatic neuroendocrine tumors (GEP-NETs): results from the National Cancer Registry of Spain (RGETNE). Ann Oncol. 2010;21:1794-803.

24. Panzuto F, Nasoni SM, Corleto VD, Capurso G, Cassetta S, Di FM, Tornatore V, Milione M, Angeletti S, Cattaruzza MS. Prognostic factors and survival in endocrine tumor patients: comparison between gastrointestinal and pancreatic localization. Endocr Relat Cancer. 2005;12(4):1083-92.

25. Falconi M, Bettini R, Scarpa A, Capelli P, Pederzoli P: Surgical strategy in the treatment of gastrointestinal neuroendocrine tumours. Ann Oncol 2001, 12 suppl 2(12 Suppl 2):S101-S103.

26. Garciacarbonero R, Jimenezfonseca P, Teulé A, Barriuso J, Sevilla I. SEOM clinical guidelines for the diagnosis and treatment of gastroenteropancreatic neuroendocrine neoplasms (GEP-NENs) 2014. Clin Transl Oncol. 2014;16(12):1025-34.

27. Lepage C, Ciccolallo LAR, Bouvier AM, Faivre J, Gatta G. European disparities in malignant digestive endocrine tumours survival. Int J Cancer. 2010; 126(12):2928-34

28. Basturk O, Yang Z, Tang LH, Hruban RH, Adsay V, Mccall CM, Krasinskas AM, Jang KT, Frankel WL, Balci S. The high-grade (WHO G3) pancreatic neuroendocrine tumor category is morphologically and biologically heterogenous and includes both well differentiated and poorly differentiated neoplasms. Am J Surg Pathol. 2015;39(5):683-90.

29. Vélayoudom-Céphise FL, Duvillard P, Foucan L, Hadoux J, Chougnet CN, Leboulleux S, Malka D, Guigay J, Goere D, Debaere T. Are G3 ENETS neuroendocrine neoplasms heterogeneous? Endocr Relat Cancer. 2013; 20(5):649-57.

30. Vilar E, Salazar R, Pérez-García J, Cortes J, Oberg K, Tabernero J, Chemotherapy and role of the proliferation marker Ki-67 in digestive neuroendocrine tumors. Endocr Relat Cancer. 2007;14(2):221-32.

\section{Submit your next manuscript to BioMed Central and we will help you at every step:}

- We accept pre-submission inquiries

- Our selector tool helps you to find the most relevant journal

- We provide round the clock customer support

- Convenient online submission

- Thorough peer review

- Inclusion in PubMed and all major indexing services

- Maximum visibility for your research

Submit your manuscript at www.biomedcentral.com/submit

) Biomed Central 